NASA/CR-Q7- 205821

$$
\begin{aligned}
& \text { FINAL } \\
& \text { IN-37.CR } \\
& 061,1 \\
& -5 i
\end{aligned}
$$

\title{
Scuffing Characteristics of High-Load Rolling/Sliding Contacts Operating in Liquid Oxygen -- Effects of materials and surface roughness
}

Technical report for the research conducted under Grant/Contract No. NAG8-1134

\author{
Submitted by \\ L. Chang \\ Department of Mechanical Engineering \\ Penn State University \\ University Park, PA 16802
}

August, 1996 


\title{
Scuffing Characteristics of High-Load Rolling/Sliding Contacts Operating in Liquid Oxygen -- Effects of materials and surface roughness
}

\author{
L. Chang \\ Department of Mechanical Engineering \\ Penn State University \\ University Park, PA 16802 \\ P. B. Hall \\ R. Thom \\ Tribology Research Branch \\ NASA Marshall Space Flight Center \\ MSFC, AL 35812
}

\begin{abstract}
This research reports on an experimental study of the effects of materials and surface roughness on the scuffing characteristics of rolling/sliding contacts cooled and lubricated with liquid oxygen. Experiments were carried out under heavy loading with a Hertzian pressure in the range of $2.0 \mathrm{GPa}$ to $3.0 \mathrm{GPa}$ and with a high rolling velocity of up to $48 \mathrm{~m} / \mathrm{s}$. For contacts between AISI $440 \mathrm{C}$ stainless-steel elements, the results showed that the scuffing behavior of the system was fairly consistent under a wide range of rolling velocity. Scuffing commenced at a small slide-to-roll ratio of around 0.02 , and the scuffing behavior of the contact was not sensitive to surface roughness for the test-sample RMS roughness ranging from $0.02 \mu \mathrm{m}$ to $0.10 \mu \mathrm{m}$. For contacts between $440 \mathrm{C}$ and $\mathrm{Si}_{3} \mathrm{~N}_{4}$ elements, on the other hand, the scuffing behavior of the system was not very consistent and somewhat unpredictable. The results were sensitive to surface roughness particularly that of the $\mathrm{Si}_{3} \mathrm{~N}_{4}$ test sample. With well polished test samples, consistent results were obtained; the level of traction was lower than that with a $440 \mathrm{C}$ toroid and scuffing did not take place up to a slide-to-roll ratio of near 0.03 . The results strongly suggest that significant hydrodynamic effect can be generated by liquid oxygen under heavy loading and high velocity conditions. The results also suggest that the hydrodynamic action is likely generated by the conventional viscous mechanism as it can be largely destroyed by a narrow circumferential surface scratch running through the central region of the contact.
\end{abstract}




\section{List of figures}

Figure 1 Schematic of the test rig

Figure 2 Surface roughness of a sample tire

((a) axial-direction roughness, (b) rolling-direction roughness))

Figure 3 Surface roughness of a sample $440 \mathrm{C}$ toroid

Figure 4 Typical traction vs. slide-to-roll ratio curves up to the points of scuffing ((a) $48 \mathrm{~m} / \mathrm{s}$, (b) $24 \mathrm{~m} / \mathrm{s}$, (c) $12 \mathrm{~m} / \mathrm{s}$ )

Figure 5 Rolling-direction surface roughness of a sample tire after a sequence of tests (No significant roughening in axial direction)

Figure 6 Surface roughness of a sample $440 \mathrm{C}$ toroid after a sequence of tests ((a) axial-direction roughness, (b) rolling-direction roughness))

Figure 7 Surface roughness of a sample $\mathrm{Si}_{3} \mathrm{~N}_{4}$ toroid

Figure 8 Traction vs. slide-to-roll ratio curves of two tests at $24 \mathrm{~m} / \mathrm{s}$

Figure 9 Traction vs. slide-to-roll ratio curves of two tests at $48 \mathrm{~m} / \mathrm{s}$

Figure 10 Traction vs. slide-to-roll ratio curves of two tests at $12 \mathrm{~m} / \mathrm{s}$

Figure 11 Surface roughness of the sample $\mathrm{Si}_{3} \mathrm{~N}_{4}$ toroid after the tests ((a) axial-direction roughness, (b) rolling-direction roughness))

Figure 12 Surface roughness of a $\mathrm{Si}_{3} \mathrm{~N}_{4}$ toroid after running-in with water ((a) axial-direction roughness, (b) rolling-direction roughness))

Figure 13 Test results with the run-in $\mathrm{Si}_{3} \mathrm{~N}_{4}$ toroid ((a) $24 \mathrm{~m} / \mathrm{s}$, (b) $48 \mathrm{~m} / \mathrm{s}$, (c) $12 \mathrm{~m} / \mathrm{s}$ )

Figure 14 Surface roughness of a super-polished $\mathrm{Si}_{3} \mathrm{~N}_{4}$ toroid

Figure 15 Surface roughness of a polished tire

((a) axial-direction roughness, (b) rolling-direction roughness))

Figure 16 Test results with the polished elements

(a) the first test at $24 \mathrm{~m} / \mathrm{s}$, (b) $48 \mathrm{~m} / \mathrm{s}$, (c) the second test at $24 \mathrm{~m} / \mathrm{s}$ )

Figure 17 Surface damage of the polished $\mathrm{Si}_{3} \mathrm{~N}_{4}$ toroid

((a) width of the scratch, (b) damage inside the scratch)

Figure 18 Surface damage of the polished tire

((a) width of the scratch, (b) damage inside the scratch) 


\section{Introduction}

Rolling-element bearings in the turbopumps of the liquid rocket engines directly operate in cryogenic fluids such as liquid oxygen and liquid hydrogen that are pumped into the combustion chamber of the engine. Since the viscosities of these fluids are extremely low, good fluid films are difficult to generate to protect the contact surfaces of the bearings (1). As a result, the bearings operate in a deep mixed-film regime of lubrication and, under high-speed conditions, are vulnerable to scuffing failure which may take place with a very small amount of sliding in the contact conjunction. Field inspections revealed that scuffing is indeed the primary failure mode of the bearings (2).

This research carries out an experimental study of the scuffing characteristics of rolling contacts cooled and lubricated with liquid oxygen $\left(\mathrm{LO}_{2}\right)$. The test rig used in the study is capable of closely simulating the contact conditions under which typical liquid-rocket-engine turbopump bearings operate. The objective of the research is to provide a set of first-hand data revealing the effects of material and surface finish on the scuffing behavior and contact performance. The study and future research in this area may lead to improved design for higher reliability and longer life of the turbopumps. In addition, the data obtained in this work are unique as the experiments were carried out under extremely low bulk temperature and with very small slide-toroll ratios. These results may motivate fundamental theoretical studies to further our understanding of the very complex mechanisms of scuffing, a subject addressed extensively by key authors such as Dyson (3) and (4), and Ludema (5). 


\section{Experiments and Results}

\section{The test rig and test conditions}

The test rig used to conduct the experiments was designed by Tevaarwerk (6). Figure 1 shows a schematic of the principal part of the rig. The tire is press-fitted onto a cylindrical hub which is mounted on a high-velocity spindle powered by an AC motor. The spherical toroid is supported by a pair of ball bearings and is brought in contact to the tire by a vertical load made up of dead weights. The toroid is driven by the tire by means of traction developed in the contact, and the conjunction is in (almost) pure rolling when the axis of the toroid, $\mathrm{Y}$, is parallel to the axis of the tire, Wd (the sliding and the traction developed to drive the toroid at this state of operation are vanishingly small). By skewing the axis of the toroid away from the axis of the tire (ie. rotation about $\mathrm{Z}$-axis), sliding is introduced into the conjunction in the form of side slip (ie. relative motion of tire surface to toroid surface along $\mathrm{Y}$-axis). The side traction force induced by the sliding is picked up by a piezo-electric load sensor. During operation of the rig, a fluid (ie. $\mathrm{LO}_{2}$ in current study) is supplied from the top of the toroid to cool and lubricate the tire/toroid conjunction and also the toroid bearings.

The radius of the cylindrical tire is $0.05 \mathrm{~m}$, and the radius of the spherical toroid is $0.01 \mathrm{~m}$. Dead weights totaling $400 \mathrm{~N}$ were applied to give a Hertzian pressure of $2.2 \mathrm{GPa}$ for test samples of AISI $440 \mathrm{C}$ stainless steel and of $2.9 \mathrm{GPa}$ for a $440 \mathrm{C}$ tire against a $\mathrm{Si}_{3} \mathrm{~N}_{4}$ toroid. Experiments were conducted for three rolling velocities of the contact conjunction. The highest velocity was $48 \mathrm{~m} / \mathrm{s}$ which, in conjunction with the applied load, closely simulates the contact conditions of typical cryogenic ball bearings. The other two velocities were $24 \mathrm{~m} / \mathrm{s}$ and $12 \mathrm{~m} / \mathrm{s}$; the intention to carry out lower-velocity tests was to examine the effects of hydrodynamics on contact scuffing.

\section{Contacts between AISI 440C stainless-steel elements}

The first part of the experiments studies the scuffing behavior of the contact between a $440 \mathrm{C}$ tire and a $440 \mathrm{C}$ toroid. Reference (7) gives the material properties of these elements at the 
cryogenic temperature. The Young's modulus is $2.08 \times 10^{11} \mathrm{~Pa}$, the Poisson's ratio, 0.26 and the hardness, $59 \mathrm{Rc}$. The applied load of $400 \mathrm{~N}$ generates a Hertzian pressure of $2.2 \mathrm{GPa}$. The tire surface was finished by fine grinding along the circumferential direction. Figure 2 shows its surface roughnesses. The RMS roughness is $0.083 \mu \mathrm{m}$ in the axial direction and is $0.014 \mu \mathrm{m}$ in the circumferential direction. The toroid surface was finished by honing to produce a fairly isotropic surface texture. Figure 3 shows its surface roughness; the RMS roughness is around $0.02 \mu \mathrm{m}$. A Form-Talysurf profilometer was used to assess the surface roughness; the Gauss filter was chosen in processing the data with a cut-off wavelength of $0.25 \mathrm{~mm}$.

The first sequence of experiments was conducted at a rolling velocity of $48 \mathrm{~m} / \mathrm{s}$. Adequate $\mathrm{LO}_{2}$ flow was supplied to ensure a fully flooded condition in the contact. The $\mathrm{LO}_{2}$ inflow was sub-cooled to around $65 \mathrm{~K}\left(-20{ }^{\circ} \mathrm{C}\right)$ by means of a heat exchanger filled with liquid nitrogen. After the tire and the toroid and their associated mechanical parts were chilled down by the running $\mathrm{LO}_{2}$ to a steady-state temperature, the test was started. It began with the contact at near rolling condition. The pure-rolling point was identified by generating a traction coefficient vs. slide-to-roll ratio curve traversing it (see Fig. 4 a). The traction coefficient was defined as the ratio of the side-slip traction force and the contact load, and the slide-to-roll ratio the side-slip velocity divided by the rolling velocity. After the pure-rolling point was identified, the test continued by increasing the slide-to-roll ratio stepwise in one direction by a small amount and the traction recorded. The test was aborted when the traction took off rapidly which was considered to be the onset of scuffing. The values of the slide-to-roll ratio and the traction coefficient immediately before this instability were taken as the scuffing condition. Figure $4 \mathrm{a}$ shows the results of a typical run. The traction coefficient increased rapidly to about 0.05 as the contact deviated from pure rolling by a very small amount. The traction then stayed relatively flat as more sliding was introduced into the contact. This low level of traction coefficient suggests that a significant portion of the applied load was supported by the fluid due to hydrodynamic action generated by the high rolling velocity. When the slide-to-roll ratio exceeded 0.01 , the system exhibited some instability as seen by a step increase in traction each time the slide-to-roll 
ratio took a step increase. Then the traction decreased back as the system tried to run-in at the current condition. The average traction shows a gradual increase in this stage terminated by the onset of scuffing. A total of ten tests were carried out at this operating condition. These tests were composed of three separate sessions, each of which was started with new test samples. Within each session, tests were repeated after the onset of scuffing was reached. Data were gathered for both positive and negative values of the slide-to-roll ratios (ie. side slips in opposite axial directions). Table 1 records the results of the ten tests. The average traction coefficient and slide-to-roll ratio at the onset of scuffing are 0.099 and 0.0188 , respectively.

The second sequence of experiments was conducted at a rolling velocity of $24 \mathrm{~m} / \mathrm{s}$. Ten tests were also carried out at this velocity. Figure $4 \mathrm{~b}$ shows the results of a typical run. The level of the traction coefficient is visibly higher than that of its higher-velocity counterpart, suggesting less $\mathrm{LO}_{2}$ hydrodynamic load support. The system also exhibited some traction instability at higher slide-to-roll ratios before the onset of scuffing. The results of the ten tests are recorded in Table 1. The average traction coefficient and slide-to-roll ratio at the onset of scuffing are 0.178 and 0.0179 , respectively. The last sequence of experiments was at a rolling velocity of $12 \mathrm{~m} / \mathrm{s}$. Figure $4 c$ shows the results of a typical run. The traction coefficient is much higher than the previous two rolling velocities, reaching a value close to the asperity friction coefficient at the onset of scuffing (the asperity friction is about $0.3(1,8)$ ). The results of the ten tests at this rolling velocity are also recorded in Table 1 . The average traction coefficient and slide-to-roll ratio at the onset of scuffing are 0.275 and 0.0210 , respectively. The traction coefficient suggests that, at this low velocity, the applied load was mainly supported by asperity contacts prior to scuffing.

Two observations of the test results in Table 1 are in order. First, the slide-to-roll ratios at the onset of scuffing are around 0.02 for all three test rolling velocities while the traction coefficients differ considerably. Second, the scatter of the scuffing conditions reduces as the rolling velocity reduces. For example, at $48 \mathrm{~m} / \mathrm{s}$ the number of tests with traction coefficients and slide-to-roll ratios lying outside $10 \%$ plus and minus of its average values are 6 and 3, 
respectively, while the number are 5 and 1 and 1 and 0 at $24 \mathrm{~m} / \mathrm{s}$ and $12 \mathrm{~m} / \mathrm{s}$, respectively. A plausible explanation to these results is as follows. First, why did scuffing take place at around 0.02 for a wide range of rolling velocity? Scuffing is initiated by local welding of $a$ sufficient number of contacting asperity pairs (3). This local welding is largely governed by the asperity temperature which is closely related to the local pressure, friction coefficient and rubbing velocity. For a higher rolling velocity, the rubbing velocity of asperity contacts is higher; however, the asperity pressure is lower and the number of asperity pairs in direct contacts are fewer due to higher $\mathrm{LO}_{2}$ load support. Thus, the higher or lower rubbing velocity, asperity pressure and number of asperity contacts at the different rolling velocities result in a similar net effect, and the number of welded asperity pairs becomes sufficient to lead to contact scuffing when the slide-to-roll ratio reached 0.02 . Second, why the scuffing conditions exhibited wider scattering at higher rolling velocities? At the rolling velocity of $12 \mathrm{~m} / \mathrm{s}$, the $\mathrm{LO}_{2}$ hydrodynamic effect was seen (Fig. 4c) to be nearly diminished when the slide-to-roll ratio was greater than 0.01 , perhaps due to local evaporation of $\mathrm{LO}_{2}$ caused by temperature rise in the contact nip. With the absence of $\mathrm{LO}_{2}$ load support, scuffing was solely governed by asperity contacts, resulting in very little scattering in the test data. At the rolling velocity of $48 \mathrm{~m} / \mathrm{s}$, on the other hand, $\mathrm{LO}_{2}$ load support was very significant. This load support was however established in a deep mixedfilm mode with an average film thickness of around 10 nanometers based on the calculations in reference (1). Thus, the scuffing process was much more complex and dynamic, giving rise to wide scattering in the test data.

It is worth noting that, for contacts between two $440 \mathrm{C}$ elements, the scuffing conditions are not very sensitive to surface roughness variations. Figures 5 and 6 show the surface roughnesses of the tire and the toroid, respectively, after a sequence of experiments conducted at all three rolling velocities. The RMS roughness increased to $0.1 \mu \mathrm{m}$ from its original value of around 0.02 $\mu \mathrm{m}$ (the increase was due to local plastic deformation rather than wear as the test duration was very short). These two test samples were used again in subsequent experiments, and the scuffing conditions were consistent with those recorded in Table 1. 


\section{Contacts between $440 \mathrm{C}$ and $\mathrm{Si}_{3} \mathrm{~N}_{4}$ elements}

The second part of the experiments studies the scuffing behavior of the contact between a $440 \mathrm{C}$ tire and a $\mathrm{Si}_{3} \mathrm{~N}_{4}$ toroid. The tire samples are taken from the same batch of the previous $440 \mathrm{C}$ on $440 \mathrm{C}$ tests. The Young's modulus of the $\mathrm{Si}_{3} \mathrm{~N}_{4}$ toroid is $3.1 \times 10^{11} \mathrm{~Pa}$, the Poisson's ratio, 0.26 and the hardness, $78 \mathrm{Rc}$. The Hertzian pressure generated by the applied load of $400 \mathrm{~N}$ is $2.9 \mathrm{GPa}$. The $\mathrm{Si}_{3} \mathrm{~N}_{4}$ toroid surface was finished by honing to produce a fairly isotropic surface texture. Figure 7 shows its surface roughness. The surface finish is not as good as its $440 \mathrm{C}$ counterpart toroid (Fig. 3). While the finishing process removed much of the peaks, the surface was left with deep groves which were difficult to polish out due to high hardness of the material. The RMS roughness of the sample is about $0.053 \mu \mathrm{m}$. Nevertheless, the surface appears to be less rough than those of the after-test $440 \mathrm{C}$ samples (Figs. 5 and 6).

The test results obtained with $\mathrm{Si}_{3} \mathrm{~N}_{4}$ toroids are much less consistent than those obtained with $440 \mathrm{C}$ toroids. A sequence of tests is presented in Figs. 8 to 10 . The tests was started with the rolling velocity of $24 \mathrm{~m} / \mathrm{s}$, and the results for the first test are shown in Fig $8 \mathrm{a}$. The system exhibited mild instability behavior similar to that with $440 \mathrm{C}$ toroid when the slide-to-roll ratio exceeded 0.01. Despite a high value of traction coefficient, however, scuffing did not initiate up to a slide-to-roll ratio of 0.028 which is $50 \%$ higher than the value at which scuffing initiated with $440 \mathrm{C}$ toroid. The test was terminated by returning to pure rolling and then resumed with negative slide-to-roll ratios. The results are shown in Fig. 8 b. At a slide-to-roll ratio of -0.027 and with a traction coefficient comparable to that of the previous test, scuffing initiated and the test was terminated by returning to pure rolling. The next two tests were carried out at a rolling velocity of $48 \mathrm{~m} / \mathrm{s}$, and the results are shown in Fig. 9. The results are fairly consistent. Scuffing initiated at a slide-to-roll ratio of around 0.021 on both plus and minus sides of the pure rolling point; the traction coefficient was around 0.1 . These values are similar to those obtained with $440 \mathrm{C}$ toroids. The last two tests were conducted at a rolling velocity of $12 \mathrm{~m} / \mathrm{s}$, and the results are shown in Fig. 10. In the first test (Fig. 10a), the traction was smooth at the level of 0.15 until the slide-to-roll ratio was increased to around 0.016 , at which point the traction increased 
continuously to around 0.3 . Such a large increase was unseen in any of the previous tests.and was interpreted as the onset of scuffing. The test was then terminated and resumed at the other side of the pure-rolling point. In this last test, the traction was smooth throughout and there was no sign of scuffing up to a slide-to-roll ratio of 0.024 with a traction coefficient above 0.3 . The surface texture of the $\mathrm{Si}_{3} \mathrm{~N}_{4}$ toroid underwent a significant change during the above sequence of six tests. Figure 11 shows the surface roughness of the sample after the tests. The short-wavelength components of the roughness and the deep grooves of the original surface (Fig. 7) were largely run out during the tests, and the resulting surface roughness patterns are very different from those of $440 \mathrm{C}$ toroid (Fig. 6). The surface roughness of the mating $440 \mathrm{C}$ tire after the tests is more or less similar to the resulting roughness after tests with $440 \mathrm{C}$ elements (Fig. 5).

Although the results were somewhat inconsistent and unpredictable among several test sessions, it was noted that the scuffing was not as severe as that with two $440 \mathrm{C}$ elements. With $440 \mathrm{C}$ elements, once scuffing initiated, it usually escalated rapidly with fast-accelerated traction and noise. Post inspection of the scuffed samples showed much widened contact tracks and signs of melting of surface materials, an indication of large-scale surface welding in the contact region. With a $\mathrm{Si}_{3} \mathrm{~N}_{4}$ toroid, on the other hand, the traction coefficient after scuffing took place often increased to around 0.3 . Further increase in traction appeared to be limited despite a high level of noise generated in the contact. The samples showed significant wear in the contact region but a lesser degree of surface melting. That the contact between a $440 \mathrm{C}$ element and a $\mathrm{Si}_{3} \mathrm{~N}_{4}$ element exhibits higher scuffing resistance than that between two $440 \mathrm{C}$ elements may be explained by the concept of energy of adhesion (9). Energy of adhesion is the energy which must be supplied to separate one unit area of interface between two materials in contact. The higher this energy, the higher the intermolecular attraction between material particles of the surfaces in contact. The contact between two identical-metal elements possesses much higher energy of adhesion than does the contact between a metal and a non-metal elements. Therefore, welding between asperities in the contact of two $440 \mathrm{C}$ elements, thus scuffing, is more severe than that of a $440 \mathrm{C}$ element and a $\mathrm{Si}_{3} \mathrm{~N}_{4}$ element. 
It is also noted that the results were sensitive to surface roughness of the $\mathrm{Si}_{3} \mathrm{~N}_{4}$ toroid. This sensitivity was studied by polishing the surfaces in contact at a low running velocity and under near pure rolling condition after a test was completed. Thereafter, a second test was carried out following the same procedure of the previous test. Traction level was often visibly reduced by this polishing process. To study the effects of surface roughness of the toroid on the scuffing conditions of the system, a run-in test was carried out with water as the coolant and lubricant. The system was run at $48 \mathrm{~m} / \mathrm{s}$ with a slide-to-roll ratio of 0.01 for 15 minutes. Figure 12 shows the surface roughness of the toroid after the run-in test. Aside from some waviness of the surface along the axial direction of the toroid, the roughness is nearly completely polished out (A similar degree of polishing was also attained on the mating $440 \mathrm{C}$ tire). A sequence of tests was then conducted with this polished toroid (in contact with an unpolished $440 \mathrm{C}$ tire), and very consistent results were obtained. Sample results are shown in Fig. 13. At all three test rolling velocities, the levels of traction were lower than their $440 \mathrm{C}$ counterparts recorded in Table 1. Furthermore, scuffing was not initiated up to a slide-to-roll ratio of nearly 0.03 . Also, the surface roughness did not show significant change after two separate sessions of tests.

To further study the effects of surface roughness, efforts were made to hand-polish the test elements. Figure 14 shows the surface texture of the polished $\mathrm{Si}_{3} \mathrm{~N}_{4}$ toroid; the RMS roughness is below $0.005 \mu \mathrm{m}$. Figure 15 shows the surface texture of the polished $440 \mathrm{C}$ tire. The tire could not be polished as smoothly as the toroid by the procedure employed as the polishing material cut into the sample to generate deep grooves. A test sequence was then carried out using the polished elements. The first test was run at $24 \mathrm{~m} / \mathrm{s}$; the results are shown in Fig. 16a. The traction level was at 0.02 which was never seen in any of the previous tests. As the slide-to-roll ratio was increased beyond 0.01 , the traction exhibited some jittering. A relatively large increase in traction was sensed at slide-to-roll ratios around 0.015. Even though the traction value was still very small, the test was terminated in fear of damaging the elements (it took a couple of weeks to polish out the toroid). The test was then resumed at $48 \mathrm{~m} / \mathrm{s}$; the results are shown in Fig. 16b. A low level of traction was recorded as the test was started. However, in the course of reaching out 
in slide-to-roll ratio, the traction suddenly jumped as the slide-to-roll ratio was increased to about 0.009 . The test was then terminated. To confirm that this was a premature scuffing behavior, an additional test was run at $24 \mathrm{~m} / \mathrm{s}$; the results are shown in Fig. 16c. Compared with Fig. 16a, the traction was much higher and scuffing initiated at a small value of the slide-to-roll ratio. The surfaces of the elements were subsequently examined to determine the cause and effect. Inspections revealed that there was a narrow scratch at the center of the contact track on each of the elements in contact. This surface damage was then analyzed. The damage on the toroid is shown in Fig. 17. The width of the scratch is less than one tenth of the contact track, and the surface points inside the scratch fluctuate severely. The surface damage on the tire is similar to that on the toroid but the width of the scratch is wider and surface-point fluctuations less severe as shown in Fig. 18. It was speculated that such surface damage was caused by the entrapment of a small foreign particle that was introduced into the contact from the $\mathrm{LO}_{2}$ flow line. The drastic increase in the traction level caused by this surface damage strongly suggests that $\mathrm{LO}_{2}$ hydrodynamic effect can be very significant under the conditions under which cryogenic turbopump bearings operate. It further suggests that the hydrodynamics is generated by the conventional viscous mechanism as it can be largely destroyed by a narrow, circumferential surface scratch running through the central region of the contact. 


\section{Conclusions}

This paper reports on the experiments conducted to study the scuffing characteristics of rolling contacts under cryogenic conditions. The experiments lead to a number of conclusions and observations regarding the effects of material and surface finish on the contact performance.

For contacts between AISI 440C stainless-steel elements, the scuffing behavior of the system was fairly consistent under a wide range of rolling velocity. With a Hertzian pressure of $2.2 \mathrm{GPa}$ experienced by typical cryogenic turbopump ball bearings, scuffing commenced at a small slide-to-roll ratio of around 0.02 . The scuffing behavior of the contact was not sensitive to surface roughness for the test-sample RMS roughness ranging from $0.02 \mu \mathrm{m}$ to $0.10 \mu \mathrm{m}$.

For contacts between $440 \mathrm{C}$ and $\mathrm{Si}_{3} \mathrm{~N}_{4}$ elements, the scuffing behavior of the system was not very consistent and somewhat unpredictable. The results are shown to be sensitive to surface roughness particularly that of the $\mathrm{Si}_{3} \mathrm{~N}_{4}$ toroid. With a properly polished toroid as shown in Fig. 12 , consistent results were obtained; the level of traction was lower than that with a $440 \mathrm{C}$ toroid and scuffing did not take place up to a slide-to-roll ratio of near 0.03 . With a super polished $\mathrm{Si}_{3} \mathrm{~N}_{4}$ toroid of a RMS roughness below $0.005 \mu \mathrm{m}$, an even low traction level was attained. This low traction strongly suggests that significant hydrodynamic effect can be generated by liquid oxygen under the conditions under which cryogenic turbopump bearings operate to support a large portion of the contact load. The experiments also revealed that the hydrodynamic action is likely generated by the conventional viscous mechanism as it can be largely destroyed by a narrow circumferential surface scratch running through the central region of the contact. 


\section{References}

(1) Hall, P. B., Chang, L. and Thom, R., "An Experimental/Analytical Study of High-Speed, High-Load Rolling/Sliding Contacts with Ultra-Low-Viscosity Fluids," STLE Tribology Transactions, Vol. 39, No. 4 (1996).

(2) Wedeven, L. D., "ATD HPOTP Pump End Ball Bearing Tribological Observations," NASA Technical Report (Contract No. NAS8-36801), Huntsville, AL (June, 1993).

(3) Dyson, A., "Scuffing - a review," Tribology International, pp. 77-87 (April 1975).

(4) Dyson, A., "Scuffing - a review Part 2: The mechanism of scuffing," Tribology International, pp. 117-122 (June 1975).

(5) Ludema, K. C., "Scuffing Review," Wear, Vol. 100, No. 3, pp. 315-331 (1984).

(6) Tevaarwerk, J. L., "Development of a Cryogenic Traction Tester," NASA Technical Report (Contract No. NAS8-38552), Huntsville, AL (September, 1992).

(7) "Material Properties Manual Volume 1," Rockwell International Corp., Canoga Park, CA (February 1987).

(8) Slifka, A. J., Compos, R., Morgan, T. J., Siegwarth, J. D. and Chaudhuri, D. K., "Tribological Behavior of $440 \mathrm{C}$ Martensitic Stainless Steel From - $184^{\circ} \mathrm{C}$ to $750^{\circ} \mathrm{C}$," Advances in Cryogenic Engineering Materials, Vol. 38A, pp. 323-330 (1992).

(9) Rabinowicz, E., Friction and Wear of Materials, John Wiley \& Sons, New York, 1965. 
Table 1 Slide-to-roll ratio and traction coefficient at the onset of scuffing

\begin{tabular}{|c|c|c|c|c|c|c|}
\hline \multirow{2}{*}{ No. } & \multicolumn{2}{|c|}{$48 \mathrm{~m} / \mathrm{s}$} & \multicolumn{2}{c|}{$24 \mathrm{~m} / \mathrm{s}$} & \multicolumn{2}{c|}{$12 \mathrm{~m} / \mathrm{s}$} \\
\cline { 2 - 7 } & $\begin{array}{c}\text { Slide/roll } \\
\text { ratio }\end{array}$ & $\begin{array}{c}\text { Traction } \\
\text { coef. }\end{array}$ & $\begin{array}{c}\text { Slide/roll } \\
\text { ratio }\end{array}$ & $\begin{array}{c}\text { Traction } \\
\text { coef. }\end{array}$ & $\begin{array}{c}\text { Slide/roll } \\
\text { ratio }\end{array}$ & $\begin{array}{c}\text { Traction } \\
\text { coef. }\end{array}$ \\
\hline 1 & 0.021 & 0.11 & 0.017 & 0.21 & 0.019 & 0.30 \\
\hline 2 & 0.018 & 0.10 & 0.017 & 0.18 & 0.021 & 0.28 \\
\hline 3 & 0.016 & 0.14 & 0.019 & 0.20 & 0.021 & 0.27 \\
\hline 4 & 0.018 & 0.11 & 0.019 & 0.23 & 0.021 & 0.23 \\
\hline 5 & 0.019 & 0.09 & 0.018 & 0.17 & 0.021 & 0.25 \\
\hline 6 & 0.018 & 0.11 & 0.018 & 0.14 & 0.022 & 0.30 \\
\hline 7 & 0.022 & 0.06 & 0.018 & 0.17 & 0.022 & 0.29 \\
\hline 8 & 0.018 & 0.10 & 0.017 & 0.16 & 0.021 & 0.30 \\
\hline 9 & 0.018 & 0.09 & 0.019 & 0.15 & 0.022 & 0.27 \\
\hline 10 & 0.021 & 0.08 & 0.018 & 0.17 & 0.021 & 0.26 \\
\hline Average & 0.0188 & 0.099 & 0.0179 & 0.178 & 0.0210 & 0.275 \\
\hline
\end{tabular}




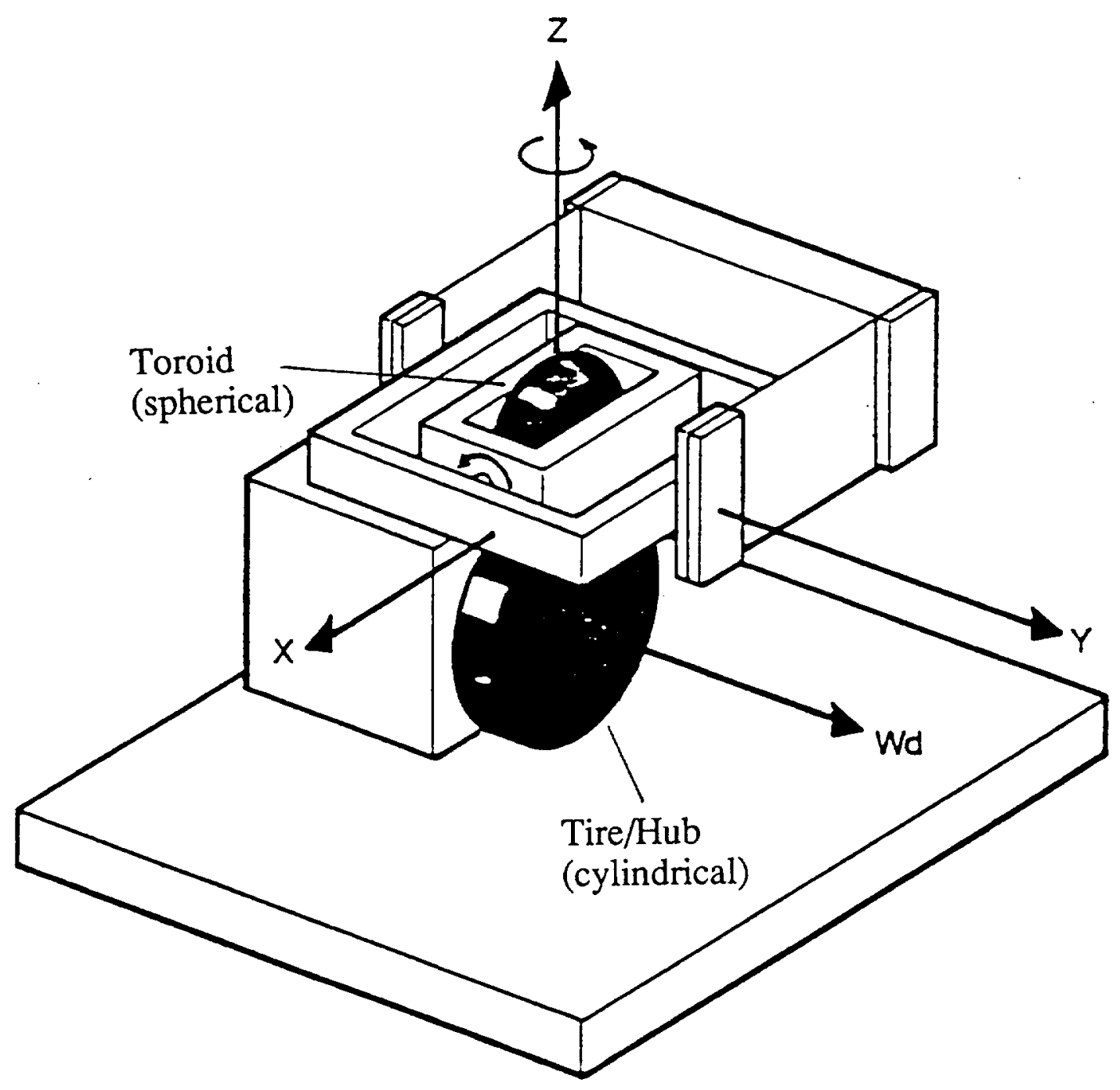

Figure 1 Schematic of the test rig 

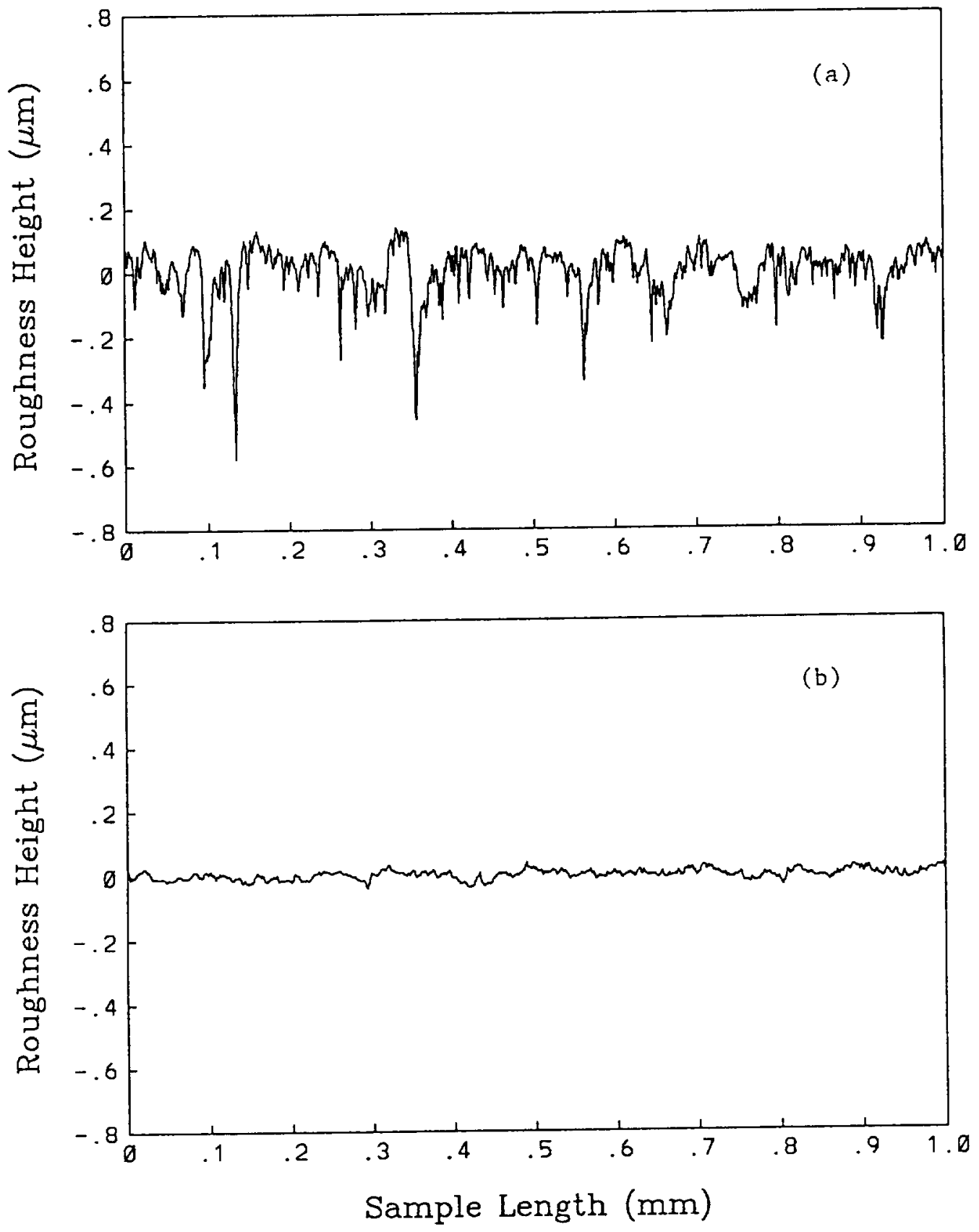

Figure 2 Surface roughness of a sample tire ((a) axial-direction roughness, (b) rolling-direction roughness)) 


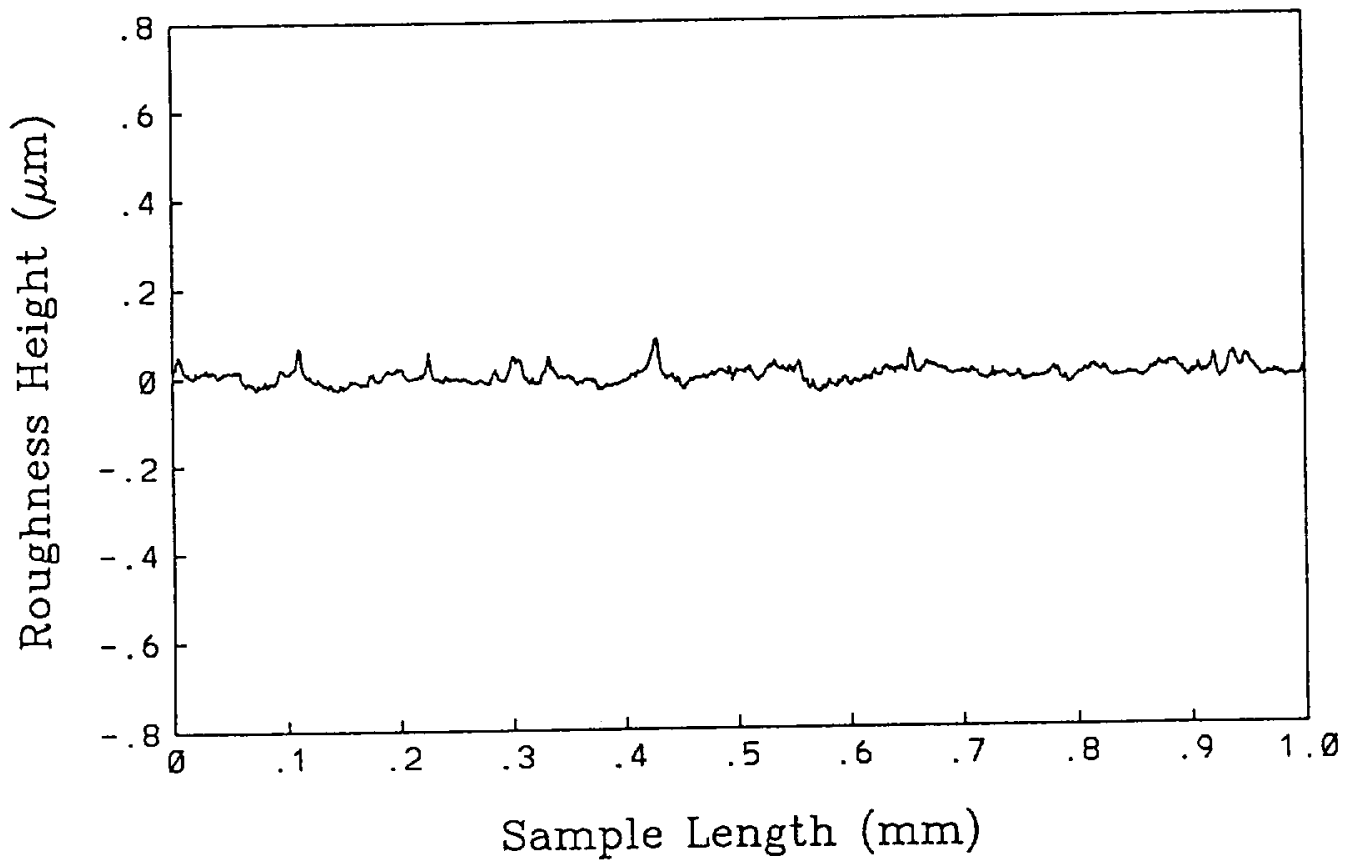

Figure 3 Surface roughness of a sample $440 \mathrm{C}$ toroid 

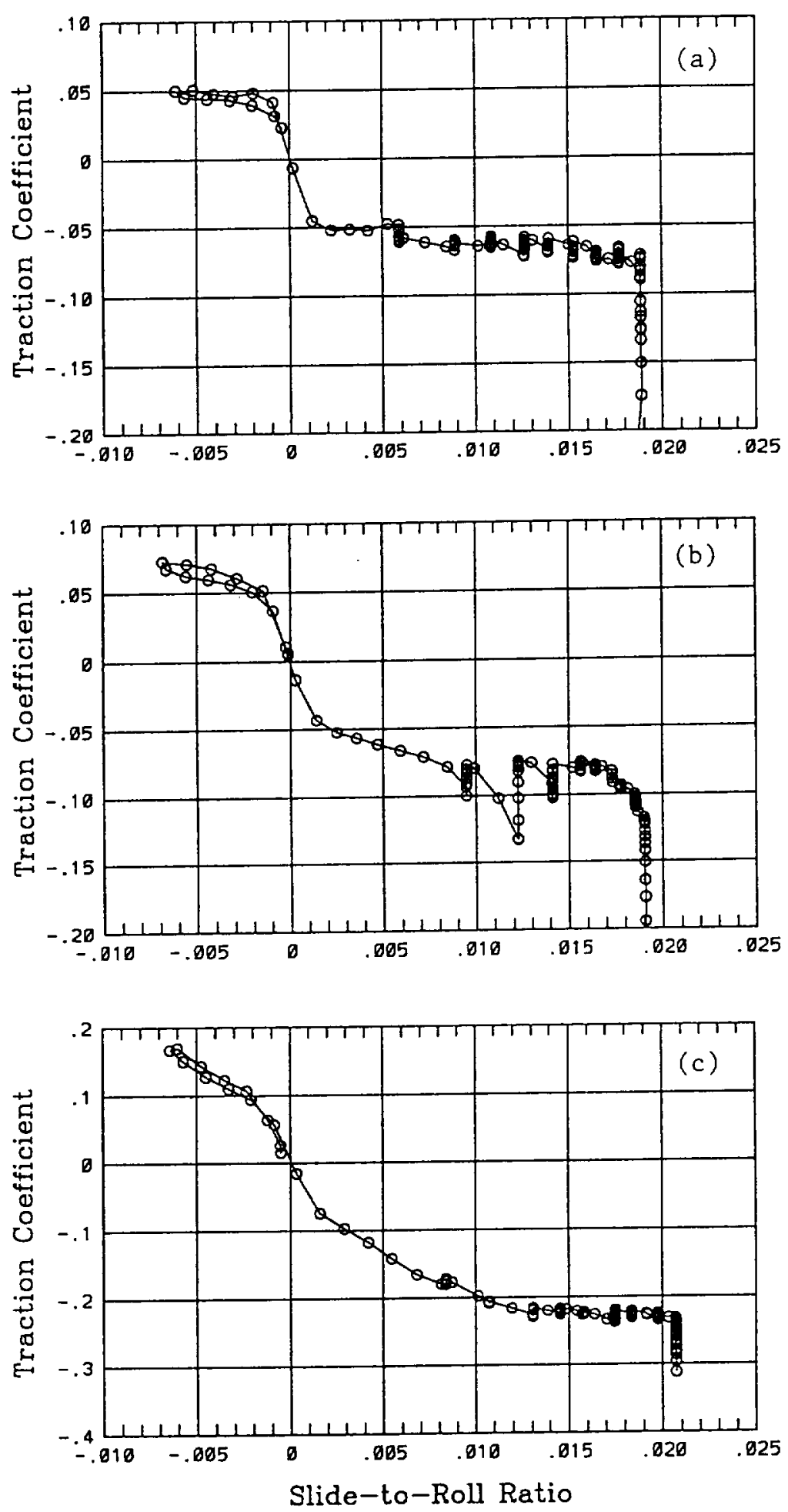

Figure 4 Typical traction vs. slide-to-roll ratio curves up to the points of scuffing ((a) $48 \mathrm{~m} / \mathrm{s}$, (b) $24 \mathrm{~m} / \mathrm{s}$, (c) $12 \mathrm{~m} / \mathrm{s}$ ) 


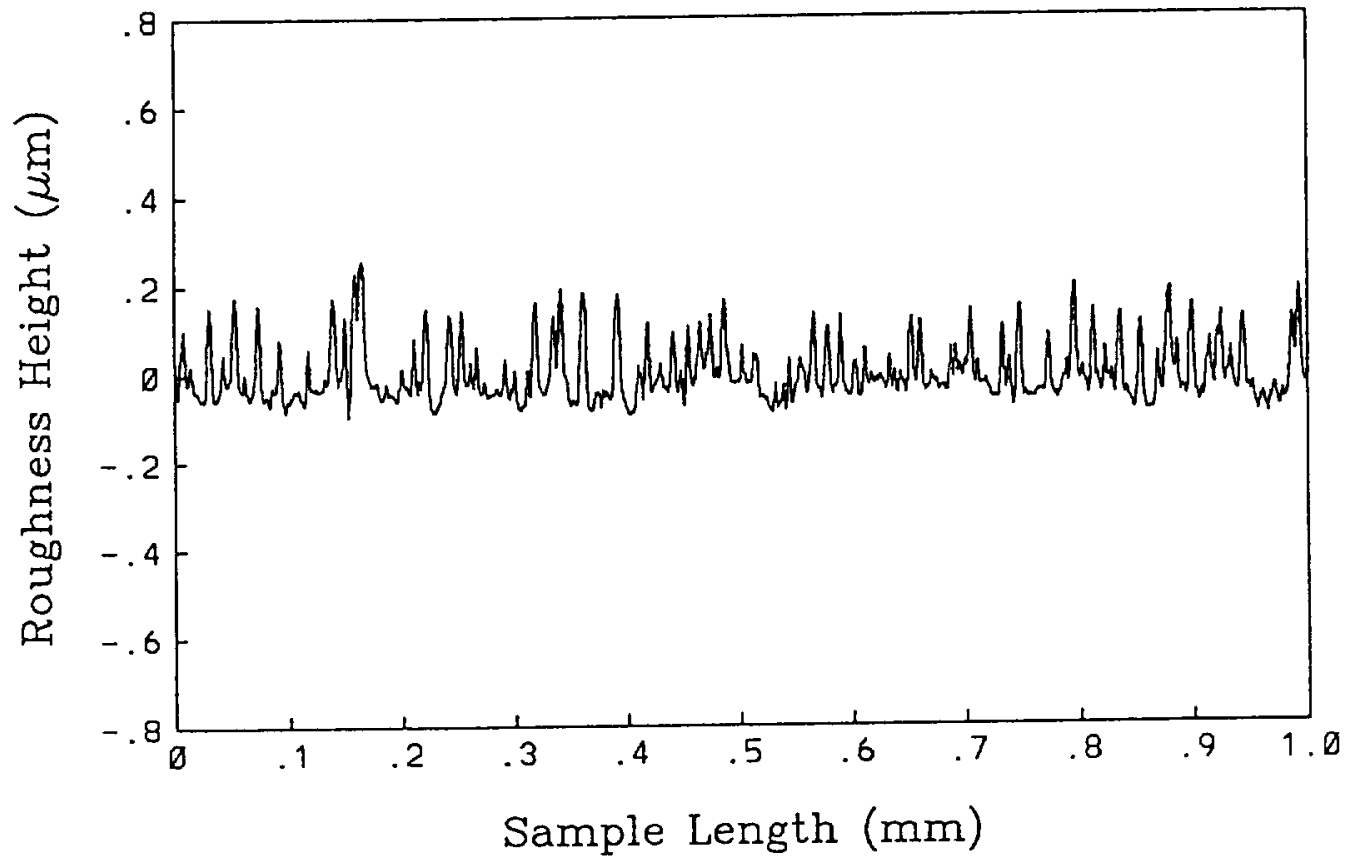

Figure 5 Rolling-direction surface roughness of a sample tire after a sequence of tests (No significant roughening in axial direction) 

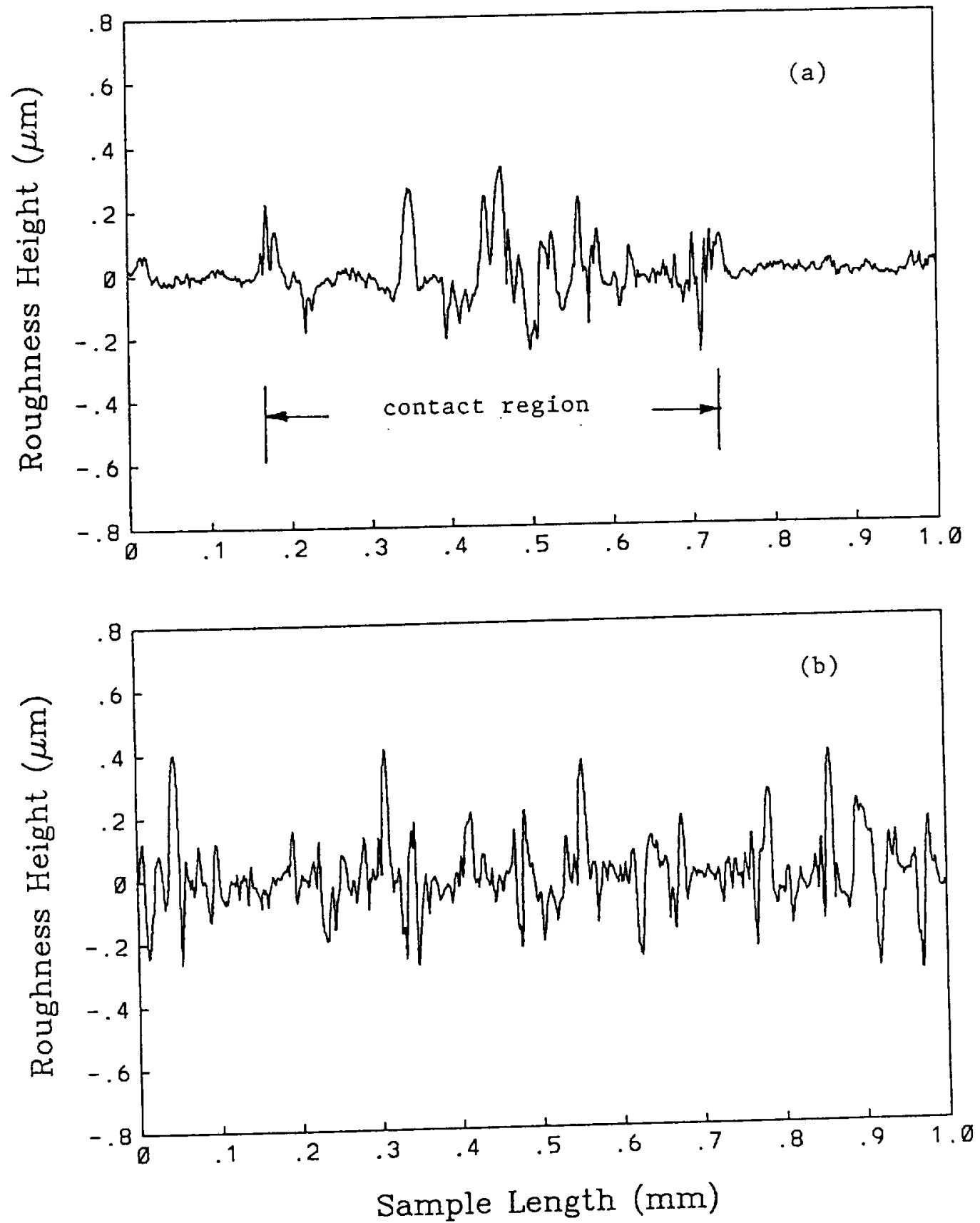

Figure 6 Surface roughness of a sample $440 \mathrm{C}$ toroid after a sequence of tests ((a) axial-direction roughness, (b) rolling-direction roughness)) 


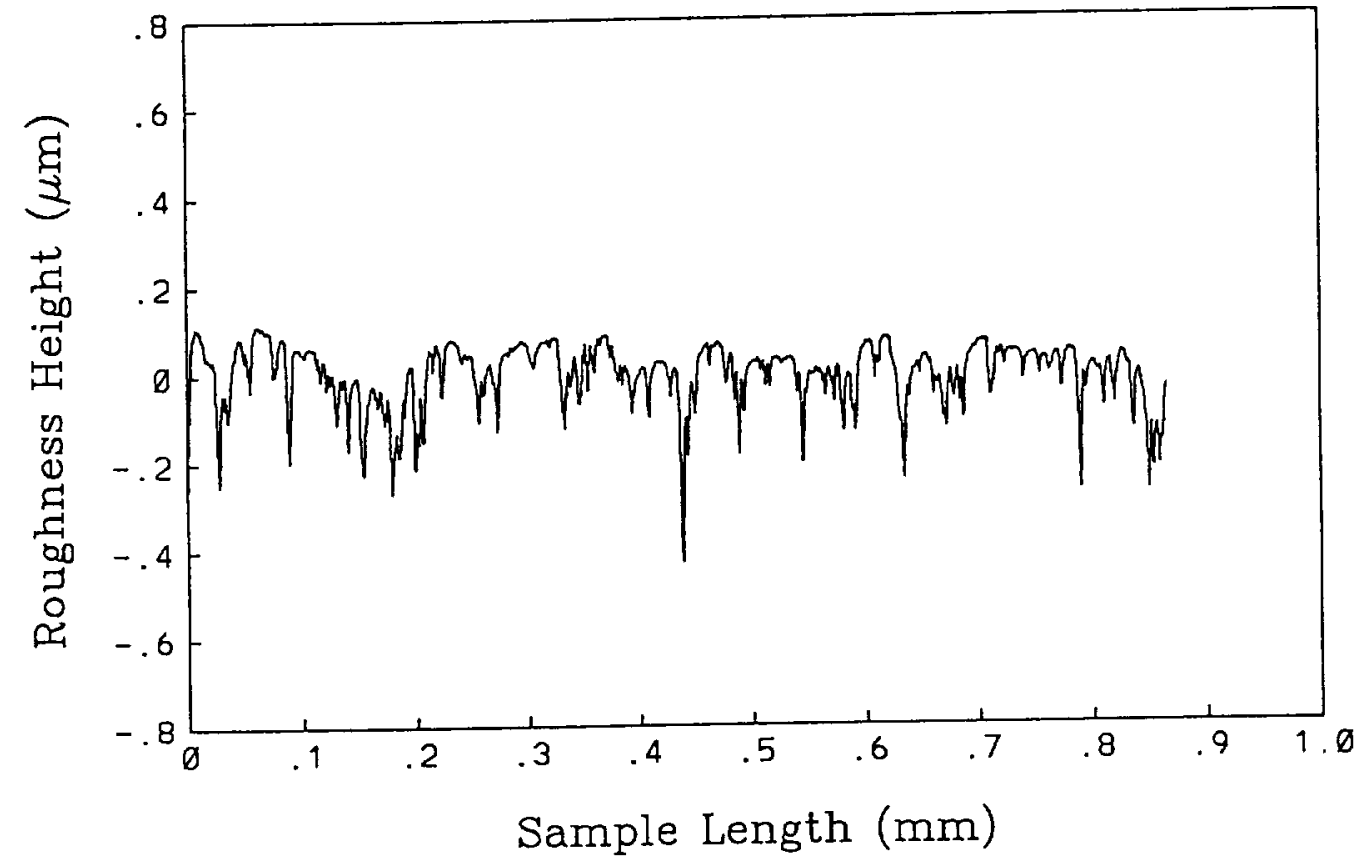

Figure 7 Surface roughness of a sample $\mathrm{Si}_{3} \mathrm{~N}_{4}$ toroid 

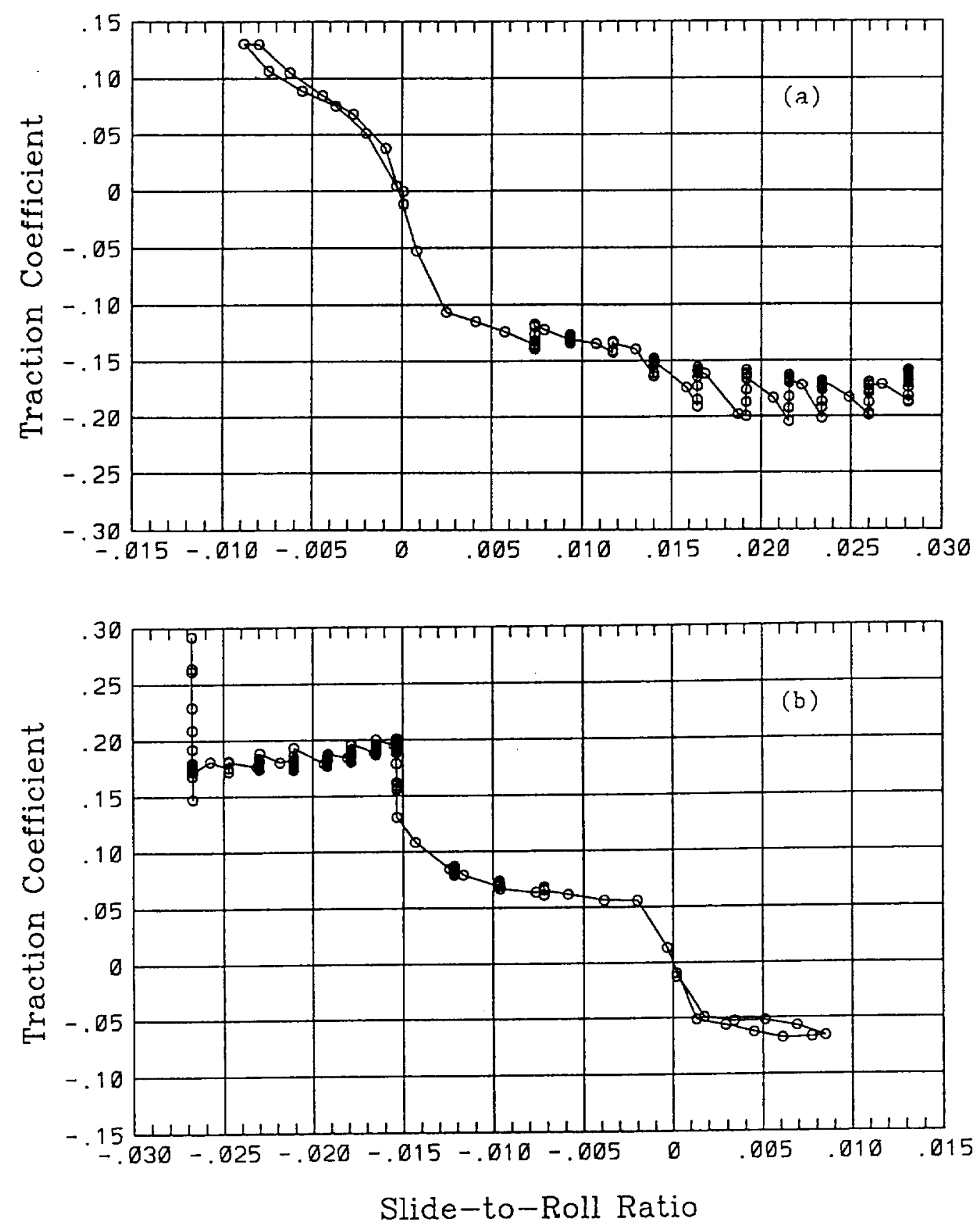

Figure 8 Traction vs. slide-to-roll ratio curves of two tests at $24 \mathrm{~m} / \mathrm{s}$ 

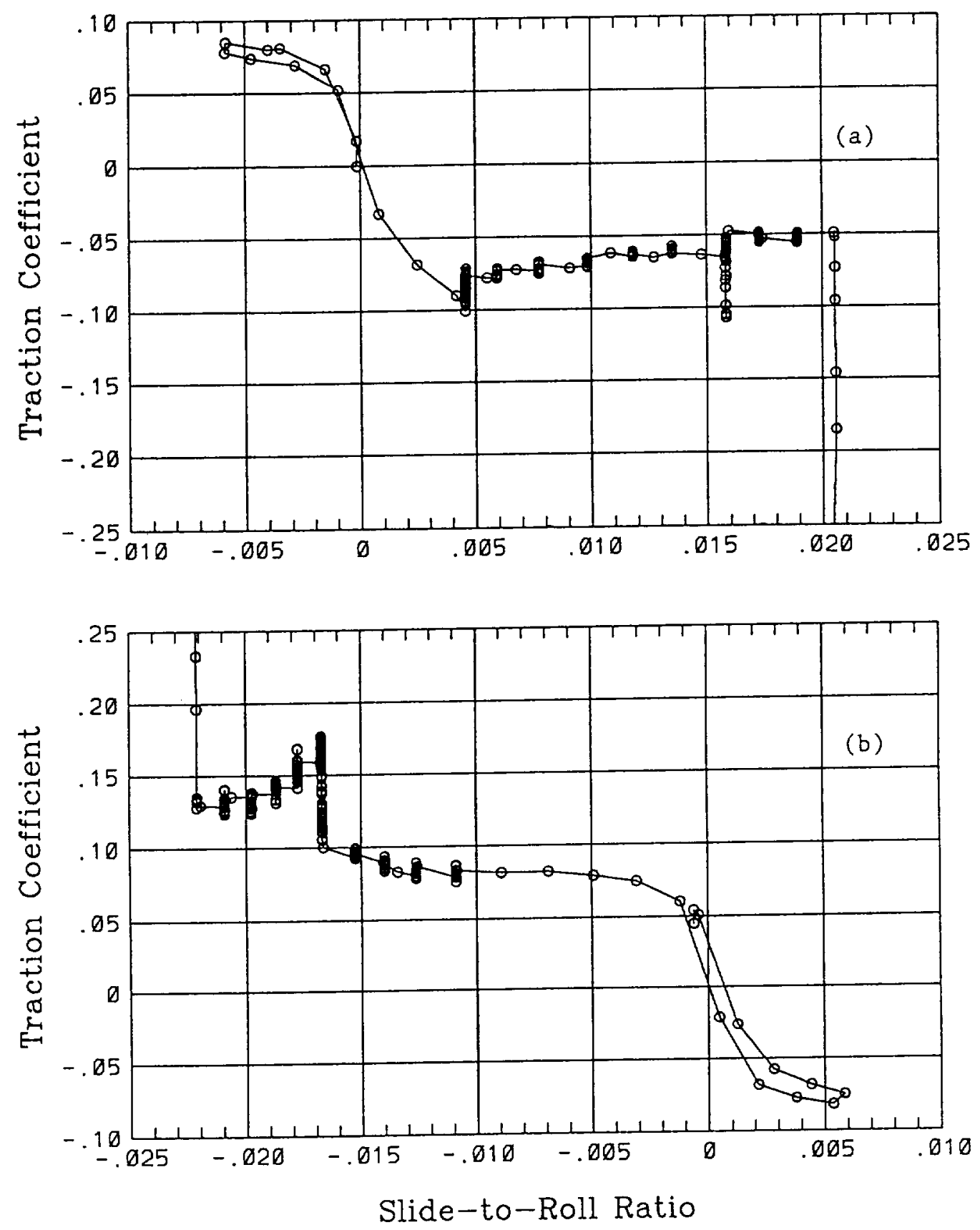

Figure 9 Traction vs. slide-to-roll ratio curves of two tests at $48 \mathrm{~m} / \mathrm{s}$ 

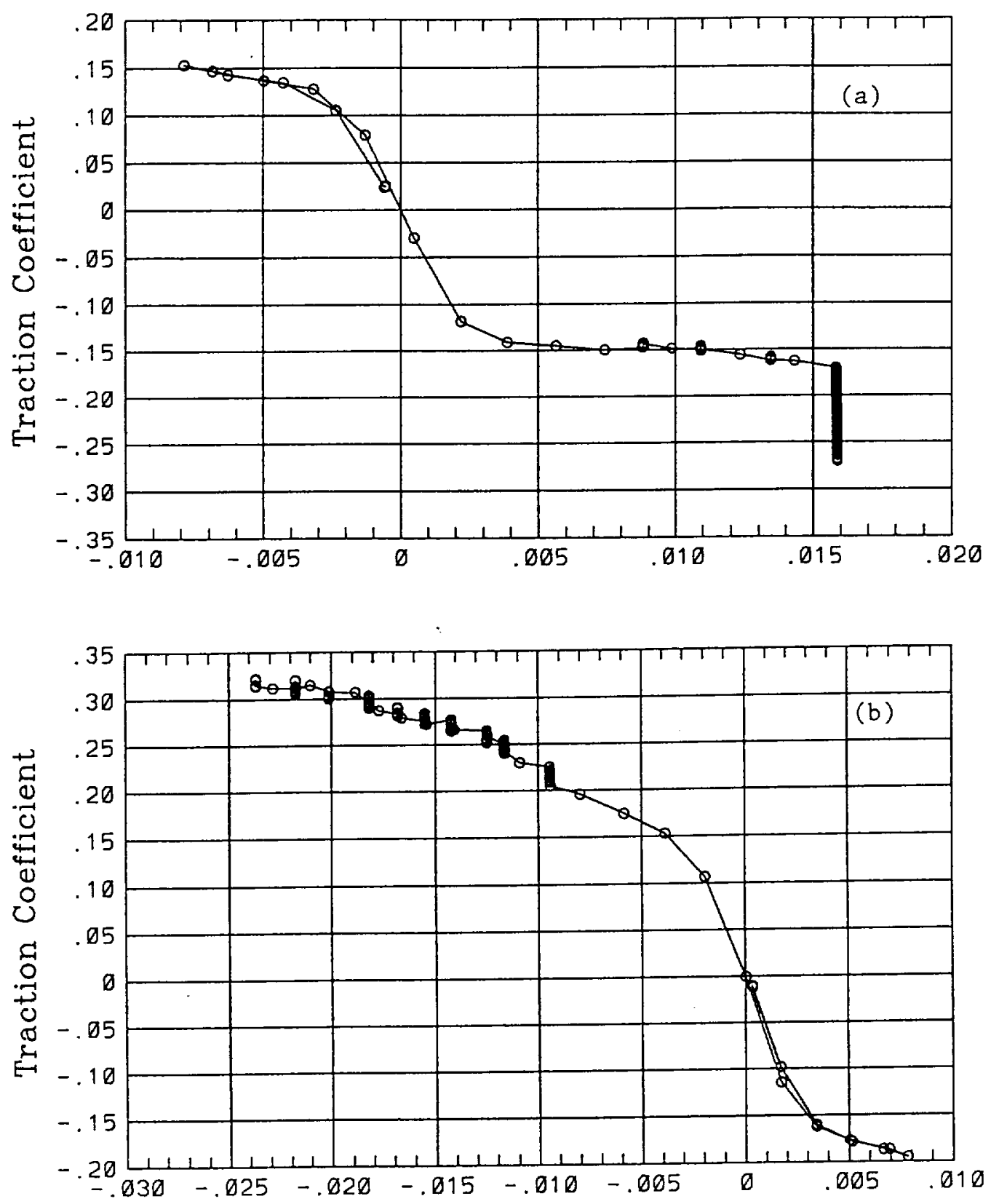

Slide-to-Roll Ratio

Figure 10 Traction vs. slide-to-roll ratio curves of two tests at $12 \mathrm{~m} / \mathrm{s}$ 

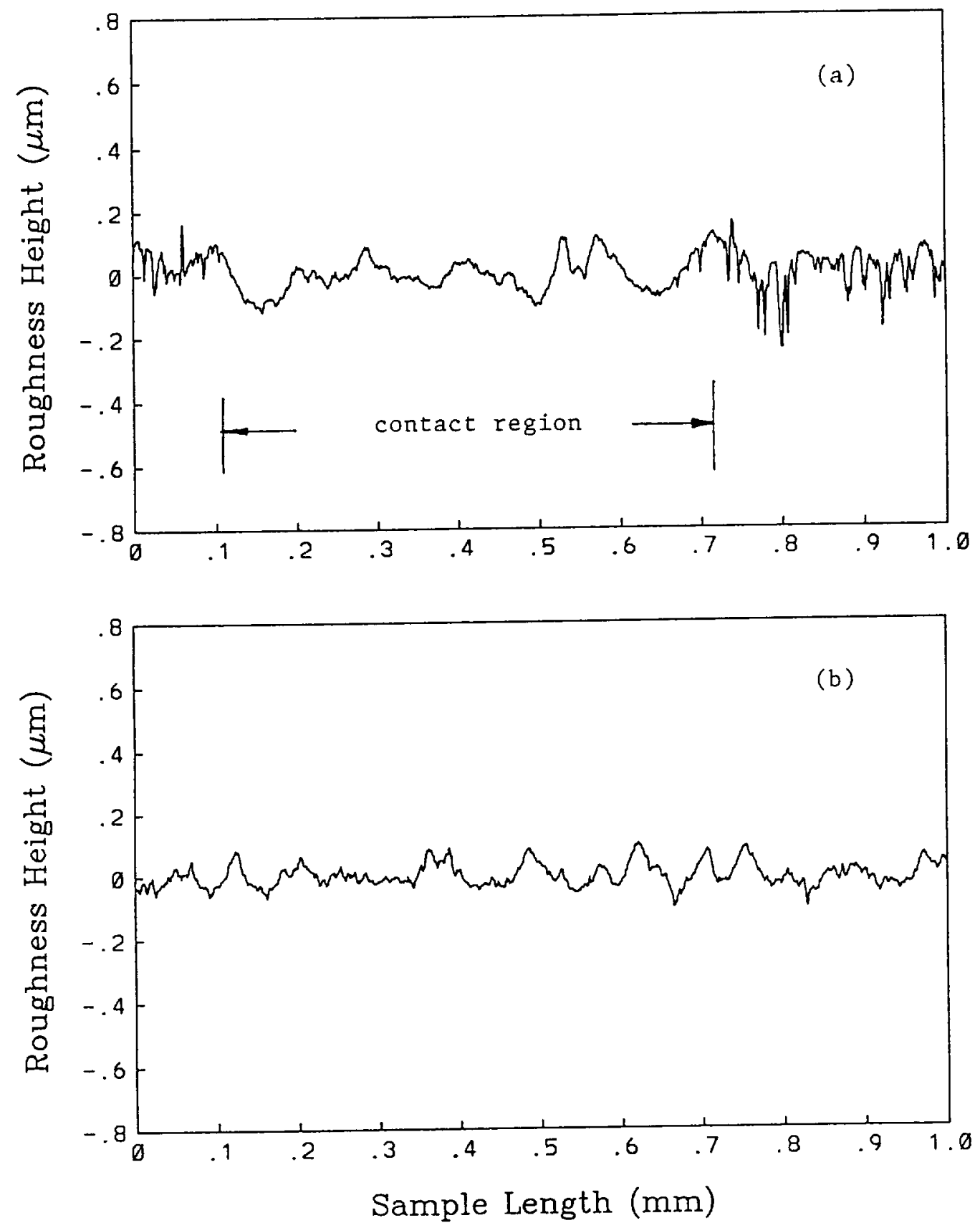

Figure 11 Surface roughness of the sample $\mathrm{Si}_{3} \mathrm{~N}_{4}$ toroid after the tests ((a) axial-direction roughness, (b) rolling-direction roughness)) 

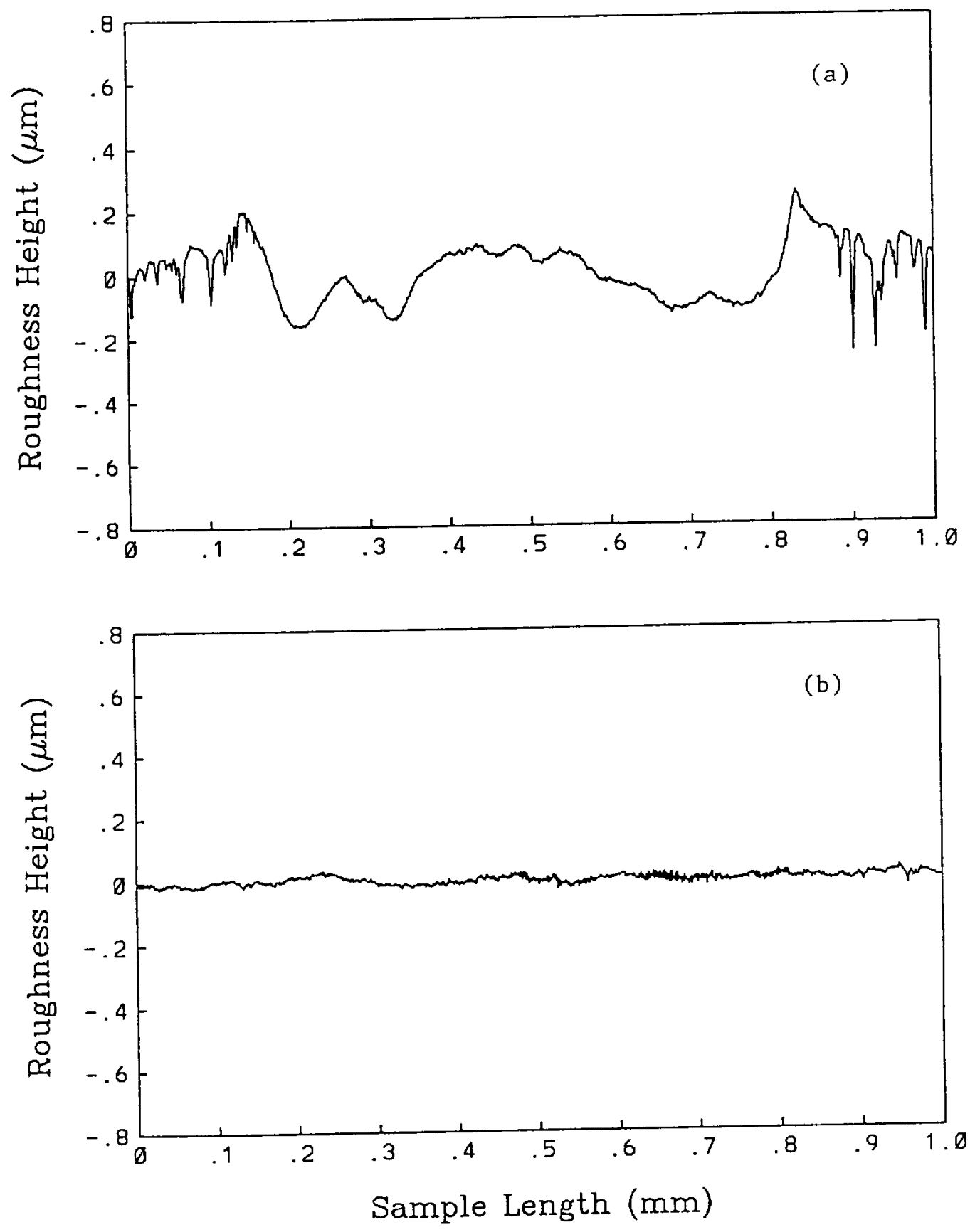

Figure 12 Surface roughness of a $\mathrm{Si}_{3} \mathrm{~N}_{4}$ toroid after running-in with water ((a) axial-direction roughness, (b) rolling-direction roughness)) 

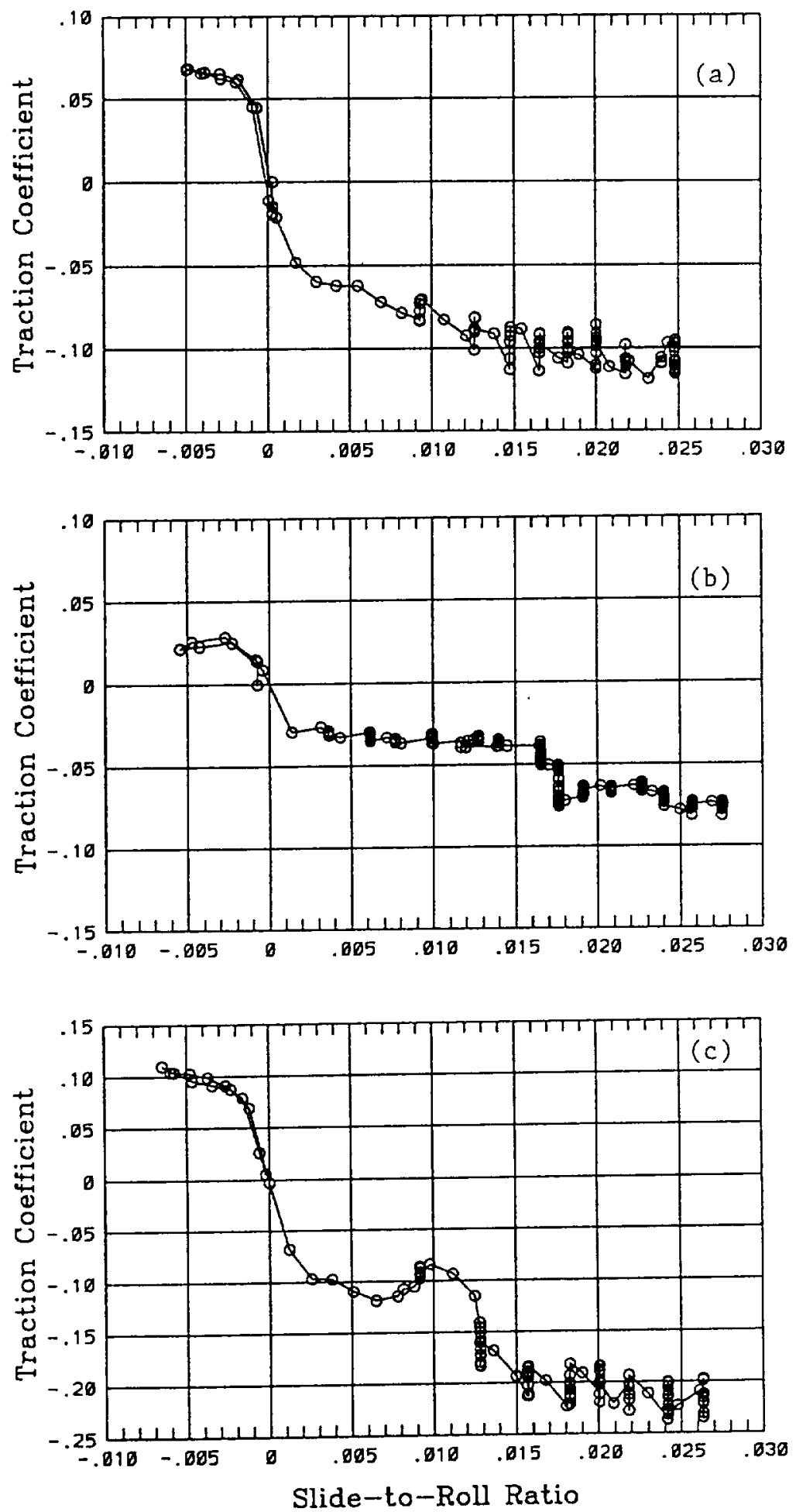

Figure 13 Test results with the run-in $\mathrm{Si}_{3} \mathrm{~N}_{4}$ toroid ((a) $24 \mathrm{~m} / \mathrm{s}$, (b) $48 \mathrm{~m} / \mathrm{s}$, (c) $12 \mathrm{~m} / \mathrm{s}$ ) 


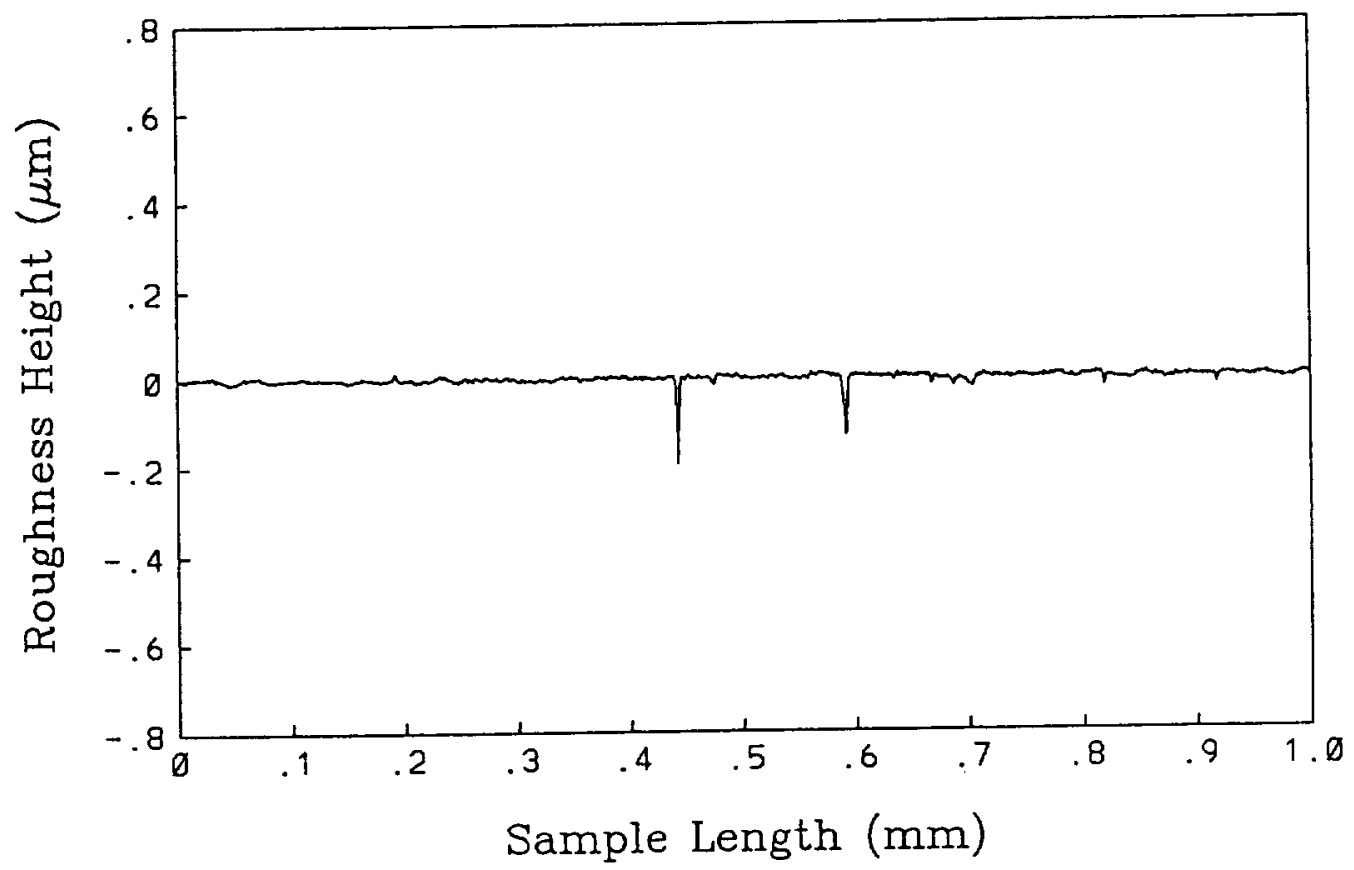

Figure 14 Surface roughness of a super-polished $\mathrm{Si}_{3} \mathrm{~N}_{4}$ toroid 

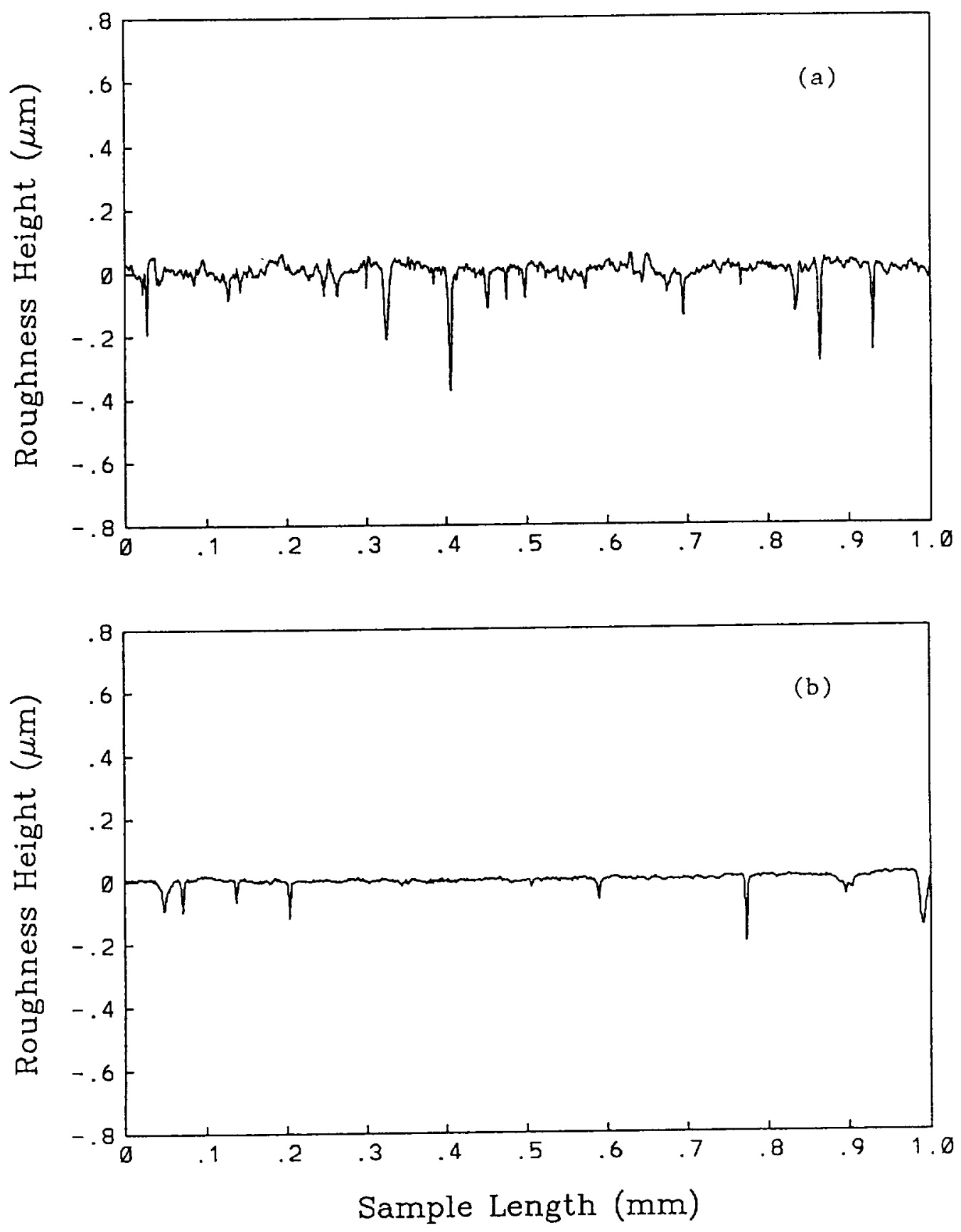

Figure 15 Surface roughness of a polished tire ((a) axial-direction roughness, (b) rolling-direction roughness)) 

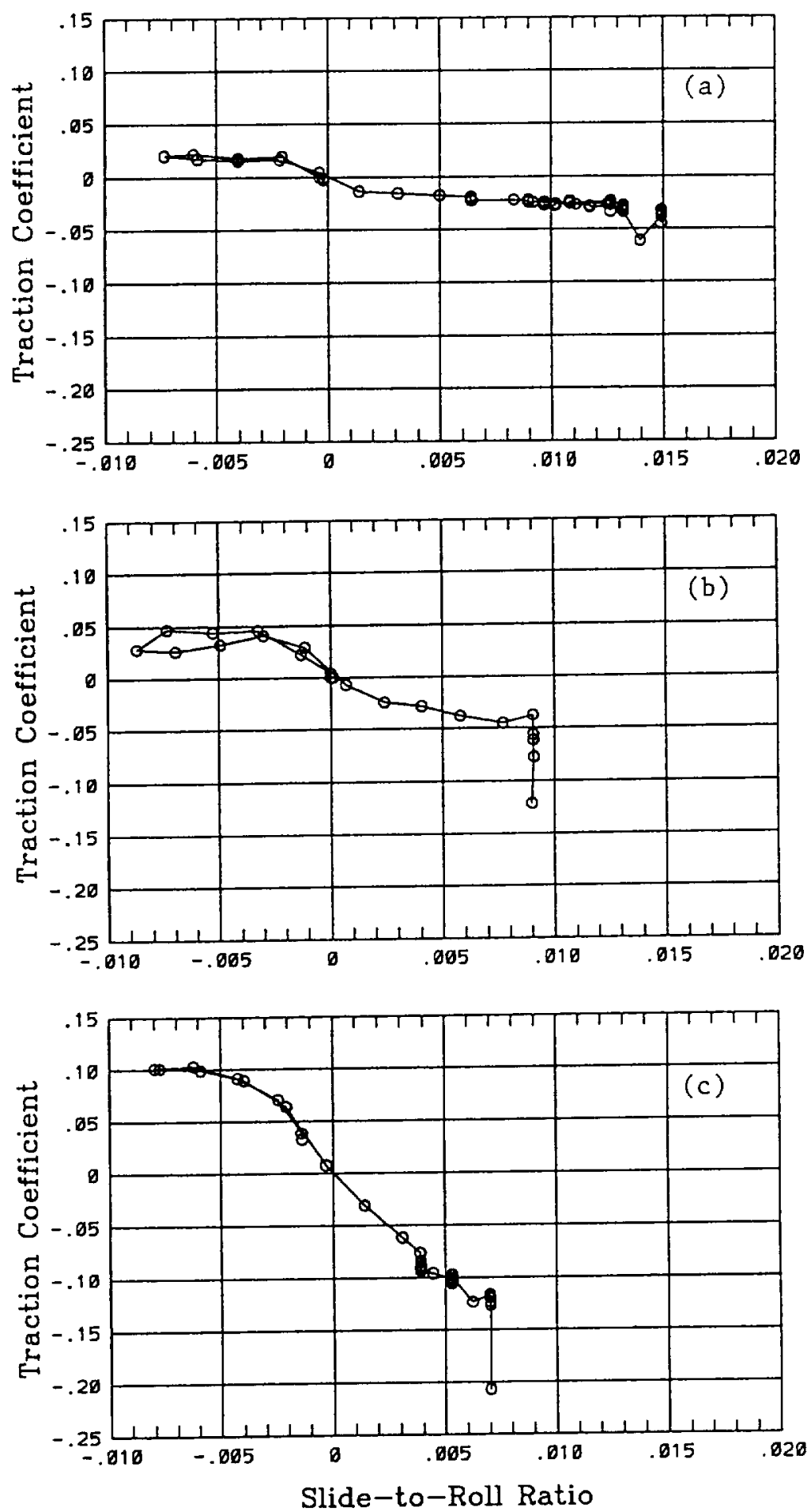

Figure 16 Test results with the polished elements

((a) the first test at $24 \mathrm{~m} / \mathrm{s}$, (b) $48 \mathrm{~m} / \mathrm{s}$, (c) the second test at $24 \mathrm{~m} / \mathrm{s}$ ) 

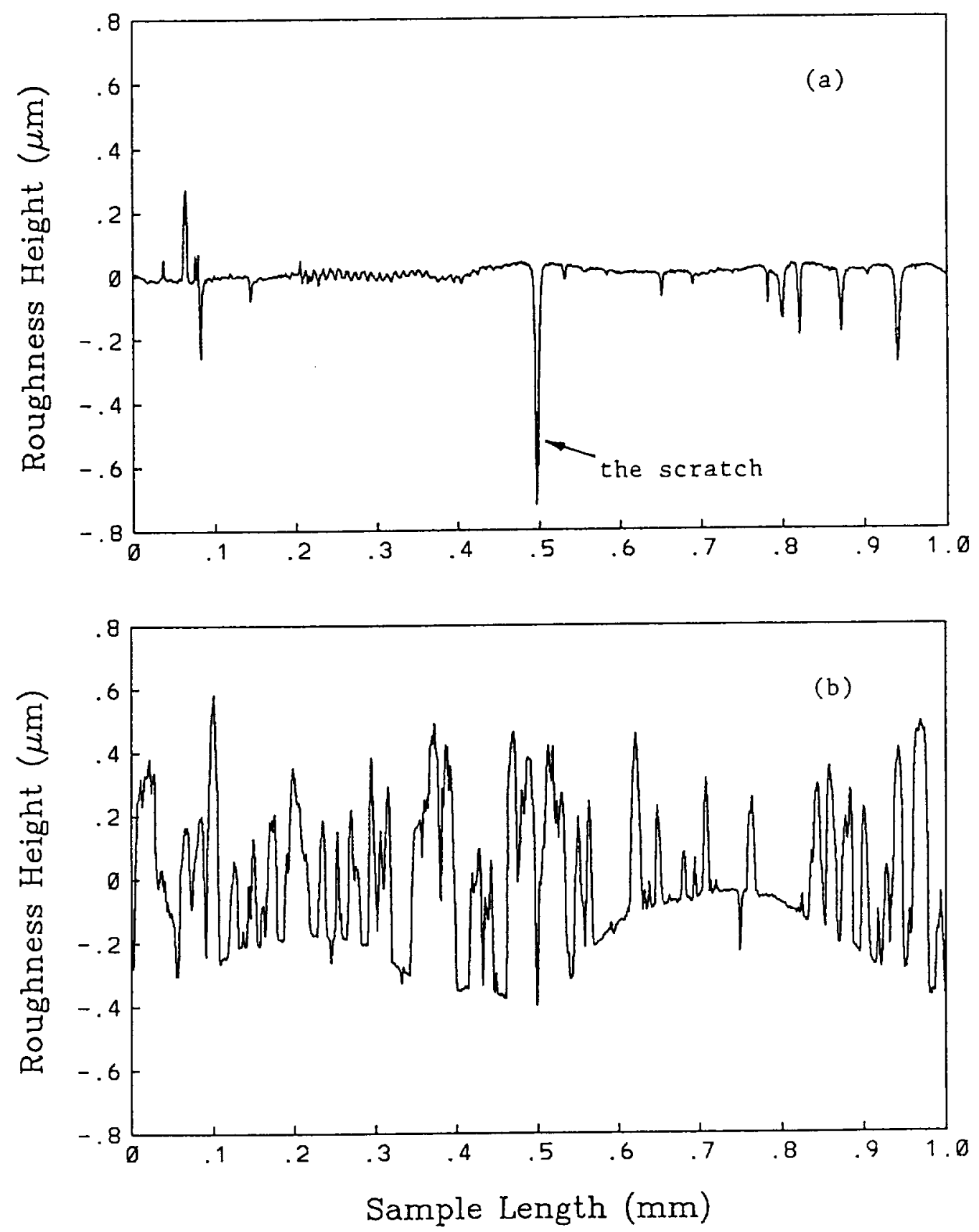

Figure 17 Surface damage of the polished $\mathrm{Si}_{3} \mathrm{~N}_{4}$ toroid ((a) width of the scratch, (b) damage inside the scratch) 

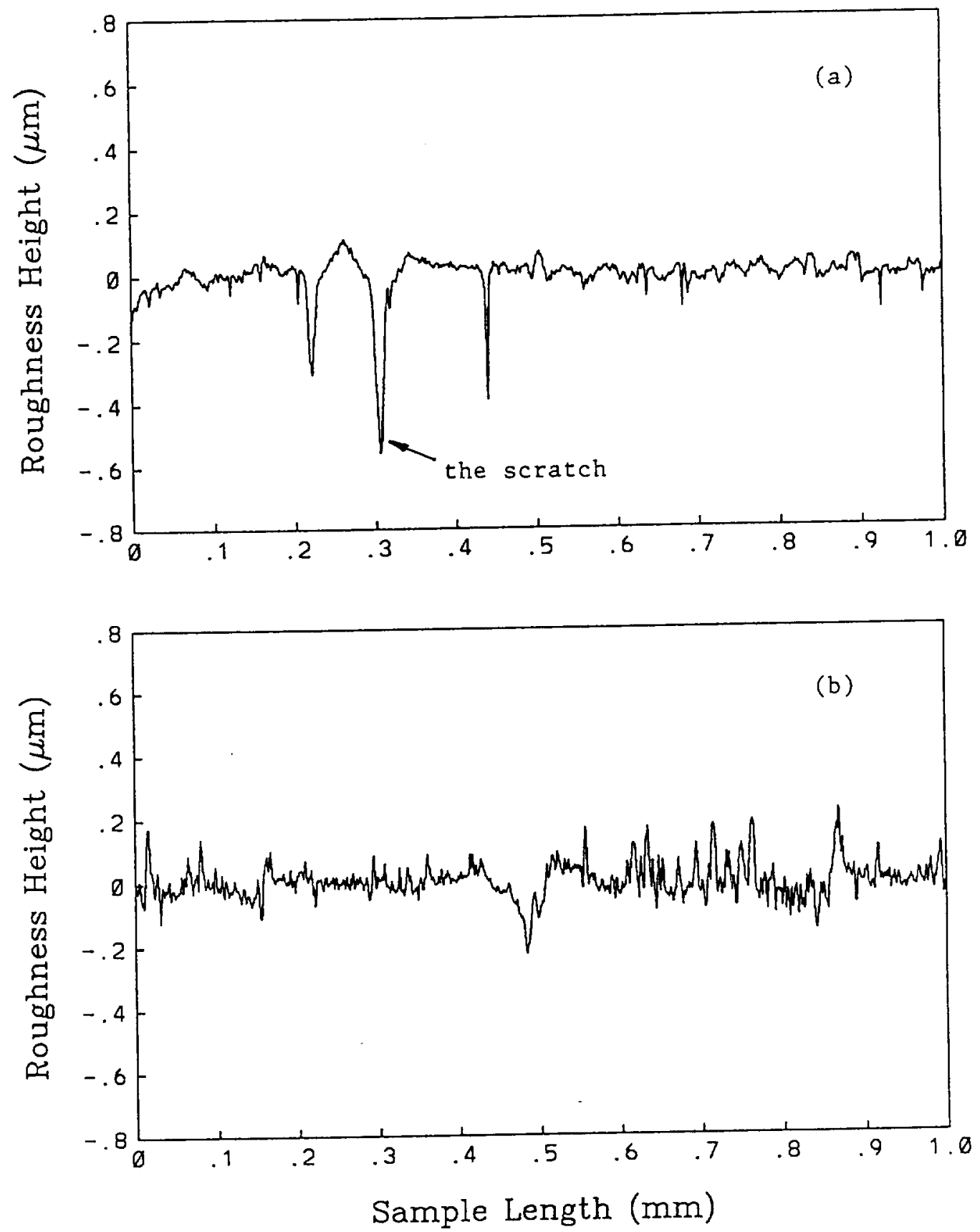

Figure 18 Surface damage of the polished tire ((a) width of the scratch, (b) damage inside the scratch) 